\title{
Assessing the educational needs of Canadian gastroenterologists and gastroenterology nurses: Challenges to optimal care in Crohn's disease
}

\author{
Martin Dupuis MA ${ }^{1}$, John K Marshall MD MSc FRCPC AGAF², Sean M Hayes PsyD ${ }^{1}$, \\ Kayla Cytryn RN PhD ${ }^{1}$, Suzanne Murray ${ }^{1}$
}

M Dupuis, JK Marshall, SM Hayes, S Murray. Assessing the educational needs of Canadian gastroenterologists and gastroenterology nurses: Challenges to optimal care in Crohn's disease. Can J Gastroenterol 2009;23(12):805-810.

OBJECTIVE: A national needs assessment of Canadian gastroenterologists and gastroenterology nurses was undertaken to determine the perceived and unperceived educational and performance barriers to caring for patients with Crohn's disease (CD).

METHODS: A triangulated, mixed-method approach (qualitative and quantitative) was used to determine the nature and extent of knowledge gaps and barriers in the care of patients with CD.

RESULTS: Qualitative interviews were conducted with nine gastroenterologists, four gastroenterology nurses and nine patients with CD. Based on this exploratory research, a survey was designed and launched nationally (37 gastroenterologists, 36 gastroenterology nurses). Findings indicated that Canadian gastroenterologists and gastroenterology nurses lacked clarity regarding their roles and responsibilities across the continuum of $\mathrm{CD}$ care, and face communication gaps within the health care team, undermining their effectiveness. Gastroenterologists identified challenges in optimal diagnosis due to unclear testing and diagnostic criteria. They recognized knowledge gaps when treating patient subgroups and in prescribing biological therapies. Furthermore, gastroenterologists self-identified gaps in skill, knowledge, and confidence in monitoring disease progression and effectively assessing response to therapy. When managing patients with CD, gastroenterologists expressed challenges with patient issues outside their domain of medical expertise, particularly with the skills needed to facilitate effective patient communication and education that would enhance adherence to recommended treatments.

CONCLUSIONS: Educational initiatives should address diagnostic and treatment guidelines, as well as enhancement of clinical performance gaps in health care team processes and the patient-professional therapeutic relationship. To impact care and patient outcomes, these initiatives must be relevant to clinical practice settings and applicable to the practice context.

Key Words: Crohn's disease; Educational needs assessment; Gastroenterologists; Gastroenterology nurses; Mixed methods research, Patient-health care professional relationship

rohn's disease (CD) is common in Canada, with estimates of prevalence ranging from 8.8 per $10^{5}$ population in British Columbia to 20.2 per $10^{5}$ in Quebec and Nova Scotia (1-3). As such, CD significantly impacts population health and the Canadian health care system. The hospital admission rate for patients with CD in 2001 was 26.9 per 100,000 patients, with an average stay of 9.1 days (4). Major surgery was required

\section{L'évaluation des besoins de formation des gastroentérologues et des infirmières en gastroentérologie au Canada : Des défis aux soins optimaux de la maladie de Crohn}

\begin{abstract}
OBJECTIF : Les auteurs ont entrepris une évaluation nationale des besoins des gastroentérologues et des infirmières en gastroentérologie (GE) du Canada afin de déterminer les obstacles perçus et non perçus à la formation et au rendement pour les soins aux patients atteints de la maladie de Crohn (MC).

MÉTHODOLOGIE : Une démarche triangulée mixte (qualitative et quantitative) a permis de déterminer la nature et l'étendue des lacunes et des obstacles en matière de savoir dans les soins aux patients atteints de la MC. RÉSULTATS : Les auteurs ont procédé à des entrevues qualitatives auprès de neuf gastroentérologues, quatre infirmières en GE et neuf patients atteints de la MC. D'après cette recherche exploratoire, ils ont conçu un sondage et l'ont diffusé sur la scène nationale ( 37 gastroentérologues et 36 infirmières en GE). Les résultats indiquent que les gastroentérologues et les infirmières en GE du Canada ne savent pas clairement quels sont leurs rôles et leurs responsabilités dans le continuum des soins de la MC, et ils affrontent des écueils de communications au sein de l'équipe soignante, ce qui mine leur efficacité. Les gastroentérologues ont souligné des défis dans le cadre d'un diagnostic optimal en raison d'un manque de clarté dans les critères d'examen et diagnostiques. Ils ont admis de lacunes de savoir lorsqu'ils traitent des sous-groupes de patients ou veulent prescrire des thérapies biologiques. De plus, les gastroentérologues ont déterminé qu'ils présentaient des lacunes en matière de compétences, de savoir et de confiance pour surveiller l'évolution de la maladie et évaluer avec efficacité la réaction thérapeutique. Lorsqu'ils prennent en charge des patients atteints de la $\mathrm{MC}$, les gastroentérologues ont exprimé des difficultés à l'égard des problèmes des patients qui se situent hors de leur champ d'expertise médicale, notamment les compétences nécessaires pour assurer des communications et une éducation efficaces avec eux afin d'optimiser l'observance des traitements recommandés.

CONCLUSIONS : Les formations devraient porter sur les lignes directrices en matière de diagnostic et de traitement et sur la correction des lacunes relatives au rendement clinique dans les processus de l'équipe soignante et de la relation thérapeutique entre le patient et le professionnel. Pour avoir des répercussions sur l'issue des patients, ces initiatives doivent être adaptées à la pratique clinique et être applicables au contexte de la pratique.
\end{abstract}

for $48 \%$ of patients who were hospitalized (4). The financial cost of work loss for patients with inflammatory bowel disease, including CD, has been estimated at $\$ 108$ million annually (5).

$\mathrm{CD}$ has further been shown to have a profound impact on patient quality of life (6). In a European survey, $75 \%$ of patients expressed satisfaction with their current therapy; however, $75 \%$ also reported that their symptoms disrupted leisure

${ }^{1}$ AXDEV Group Inc, Brossard, Quebec; ${ }^{2}$ Department of Medicine, Division of Gastroenterology and Farncombe Family Digestive Health

Research Institute, McMaster University, Hamilton, Ontario

Correspondence and reprints: Martin Dupuis, AXDEV Group Inc, Suite 210, 8 Place du Commerce, Brossard, Quebec J4W 3H2.

Telephone 450-465-2011, fax 450-465-1155, e-mail dupuism@axdevgroup.com

Received for publication February 18, 2009. Accepted April 22, 2009 
activities (6). Physicians may routinely underestimate the impact of CD - $61 \%$ of European patients reported that they had never been asked how CD symptoms affected their quality of life (6).

The challenge for gastroenterologists is to optimally diagnose CD and develop effective management strategies for individual patients to monitor and manage their condition. However, knowledge gaps and practice barriers interfere with the delivery of optimal patient care by gastroenterologists and gastroenterology (GI) nurses. Gastroenterologists often rely on 'trial and error', patient self-reports and clinical judgment to determine whether patients are benefiting from a particular therapy and to what extent (7). Gaps in knowledge, skill, attitude and practice relate not only to medical knowledge and expertise, but also to health care professionals' skill in interacting with and meeting patients' educational and psychosocial needs. In addition, patient care is provided in the context of a health care system in which gastroenterologists and GI nurses function as integral members of interdisciplinary health care teams. These competencies include the larger context of care (ie, skill in interacting with and educating patients) and collaborating with colleagues and other members of the health care team are emphasized in the Canadian Medical Education Directives for Specialists (CanMEDS) 2005 Physician Competency Framework (8) in Canada, as well as by professional organizations in the United States $(9,10)$.

Despite the high incidence of CD in Canada, the educational needs of Canadian gastroenterologists and GI nurses who manage patients with $\mathrm{CD}$ have received little attention. Identifying the teams' clinical challenges and perceived and unperceived educational needs can, in turn, inform the development of educational initiatives that target practice change and ultimately improve patient outcomes. To identify these educational needs, an educational and behavioural needs assessment was conducted from March to July, 2008. The target audiences were Canadian gastroenterologists and GI nurses in clinical practice. Because the present study focused on challenges and needs, areas in which participants have reported adequate patient care were not addressed.

\section{METHODS}

Drawing from the tenets of mixed methods research, both qualitative and quantitative data collection techniques were used in the present study to enhance the reliability of findings (11-13). A triangulated research design that combined data sources produced the strongest and most valid evidence (13). The study included gastroenterologists, GI nurses and a sample of patients, and used qualitative interviews and quantitative survey data collection techniques $(13,14)$. Patients were included to assess their experience receiving care for CD and to obtain a broader perspective of the challenges and needs of gastroenterologists and GI nurses. Selective sampling was applied to ensure that the sample was representative of the target audience $(13,14)$; thus, further strengthening the analysis.

Institutional review board approval was obtained (through IRB Services, Canada) for all aspects of the study to ensure the protection of human subjects with respect to anonymity and confidentiality, and to enhance the credibility and integrity of the findings.

\section{Qualitative data collection}

Recognized best practices and challenges in the care of patients with CD were determined based on a comprehensive literature review. Based on this framework, a comprehensive, openended, semistructured interview guide was developed to explore the practices and experiences of gastroenterologists and GI nurses, as well as to assess the experience of patients who have received $\mathrm{CD}$ care. Interviews were approximately $60 \mathrm{~min}$ long and were audio recorded.

Inclusion criteria for gastroenterologists and GI nurses required that they saw a minimum of $10 \mathrm{CD}$ patients per month. Patients who participated in the study were Canadian adults older than 18 years of age who had been diagnosed with CD for a minimum of two years, had seen a health care professional at least twice in the past year and had been referred to a gastroenterologist.

\section{Quantitative data collection}

A quantitative survey based on the substantive findings of the qualitative data collection phase of research was developed. The survey was forwarded to 213 Canadian gastroenterologists between June and July, 2008. A total of 37 surveys were completed (a response rate of $17.4 \%$ ). GI nurses were recruited through the Canadian Society of Gastroenterology Nurses and Associates, also between June and July, 2008. Thirty-six GI nurses completed the survey.

The sample distribution for qualitative and quantitative phases is detailed in Table 1.

\section{Analysis}

Qualitative data were audio recorded and analyzed. Coding of the qualitative data was based on grounded theory, in which concepts are drawn from the data (15). Initially, open coding was performed by reviewing the qualitative data (16) in detail based on the conceptual framework and research questions identified above.

Coding categories were then grouped into related themes and subthemes. Themes were validated among coders and discrepancies were resolved through discussions until consensus was reached. Concordance was achieved in all cases. Selective coding was then conducted (16), whereby data were systematically coded with respect to core concepts identified in the literature review and analysis of interview data.

Quantitative questions consisted of agreement ratings with survey items on a five-point Likert-type scale and gap analysis, in which participants rated both their current level and desired level of knowledge, skill and attitudes. The difference (ie, gap), between current and desired levels provided an indicator of specific areas of educational need (11). These data were analyzed using descriptive statistics (frequencies), ANOVA and gap analysis with SPSS 12.0 statistical software (SPSS Inc, USA).

\section{RESULTS}

\section{Sample size and demographics}

A total of 46 Canadian gastroenterologists (approximately 10\% of gastroenterologists in Canada) and 40 GI nurses participated in the behavioural needs assessment (Table 1). Approximately $35 \%$ of gastroenterologists had less than 10 years of clinical practice experience, $37 \%$ had 11 to 20 years of experience and $29 \%$ had more than 21 years of experience. Among GI nurses, 22\% had less than 10 years of experience, $19 \%$ had 11 to 20 years of 
experience and $62 \%$ had practiced for more than 21 years. Approximately $58 \%$ of gastroenterologists practiced in the community as opposed to an academic setting. The majority $(67 \%)$ of GI nurses practiced in an academic setting. Nine patients were interviewed during the qualitative phase of research.

\section{Gaps in access to care}

Gaps that impact patients' access to all stages of clinical care for gastrointestinal-related symptoms, from initial assessment to patient management, were evaluated. According to gastroenterologists, GI nurses and patients, gastroenterologists and GI nurses have become the 'de facto' primary care physicians (PCPs) and caregivers for patients with CD. Gastroenterologists attributed this role to family physicians' lack of knowledge and confidence in making decisions on behalf of patients with CD due to the nonspecific nature of disease symptoms and lack of straightforward treatment options and clear methods for disease monitoring.

Gastroenterologists and GI nurses perceived that PCPs' lack knowledge of optimal treatment options for patients with CD. As stated by a gastroenterologist in an interview excerpt:

"I really don't see a lot of family physicians comfortable making a decision about the management of Crohn's disease. So, unfortunately, a lot of those decisions get passed on to us as gastroenterologists."

Gastroenterologists and GI nurses reported that PCPs tend to overprescribe steroids and attempt a 'quick fix' when treating patients, leaving decisions regarding long-term treatment to specialists.

Gastroenterologists and GI nurses stated that incomplete referral notes hamper the gastroenterologist's ability to recognize the urgency of a patient's case, resulting in delayed assessment and diagnosis, and increasing patient frustration with wait lists.

Patients provided corroborative evidence to the gastroenterologists and GI nurses, reporting that no clear continuum of care exists for patients with CD. As one patient noted:

"I went to my family physician after the fourth fistula and said, 'I need to see a gastroenterologist' - and he got mad at me!"

\section{Gaps in assessment and diagnosis}

Gastroenterologists and GI nurses believed that because gastroenterologists are challenged to deliver a precise diagnosis of $\mathrm{CD}$ in a timely fashion, delays or inaccuracies in diagnosis result, thereby increasing patient frustration with the assessment process.

Among the barriers to timely diagnosis were patients' perception of their symptoms as 'private', their belief that CD is 'not a sexy disease', their inability to define abnormal abdominal pain and their lack of understanding of when to seek medical consultation for diarrhea. Gastroenterologists and GI nurses both reported that patients tend to postpone consultation until severe symptoms develop. They also reported that patients found it difficult to clearly describe their symptoms, especially pain.

Disease factors presenting a challenge to optimal diagnosis by gastroenterologists included the unspecific nature of symptoms, such as the overlap of symptoms in CD and other inflammatory bowel diseases. As stated by a gastroenterologist:
TABLE 1

Characteristics in qualitative and quantitative phases of research

\begin{tabular}{|c|c|c|}
\hline \multicolumn{3}{|c|}{ Health care professionals $(n=86)$} \\
\hline & \multicolumn{2}{|c|}{ Research phase } \\
\hline Characteristic & $\begin{array}{c}\text { Qualitative: } \\
\text { Interview (Phase I) }\end{array}$ & $\begin{array}{c}\text { Quantitative: } \\
\text { Survey (Phase II) }\end{array}$ \\
\hline \multicolumn{3}{|l|}{ Profession } \\
\hline Gastroenterologist & 9 & 37 \\
\hline Gastroenterology nurse & 4 & 36 \\
\hline \multicolumn{3}{|l|}{ Age range, years* } \\
\hline $30-44$ & 4 & 27 \\
\hline $45-59$ & 4 & 40 \\
\hline $60-74$ & 2 & 5 \\
\hline \multicolumn{3}{|l|}{$\mathrm{Sex}^{\star}$} \\
\hline Male & 8 & 31 \\
\hline Female & 5 & 41 \\
\hline \multicolumn{3}{|c|}{ Patients with Crohn's disease seen per month* } \\
\hline$<11$ & 2 & 9 \\
\hline $11-25$ & 4 & 20 \\
\hline $25-50$ & 3 & 23 \\
\hline$>50$ & 1 & 20 \\
\hline \multicolumn{3}{|l|}{ Practice, years* } \\
\hline $0-5$ & 2 & 6 \\
\hline $6-10$ & 1 & 14 \\
\hline $11-20$ & 4 & 23 \\
\hline$>20$ & 4 & 21 \\
\hline \multicolumn{3}{|c|}{ Patients $(n=9)$} \\
\hline \multicolumn{3}{|l|}{ Age range, years } \\
\hline 18-29 & 2 & \\
\hline $30-39$ & 4 & \\
\hline $40-49$ & 3 & \\
\hline \multicolumn{3}{|l|}{ Sex } \\
\hline Male & 5 & \\
\hline Female & 4 & \\
\hline \multicolumn{3}{|c|}{ Visits to health care professionals in one year for Crohn's disease ${ }^{\dagger}$} \\
\hline $1-5$ & 3 & \\
\hline $6-10$ & 3 & \\
\hline$\geq 11$ & 1 & \\
\hline
\end{tabular}

Data are presented as $n$. *Totals do not add to 86 due to missing data; ${ }^{\dagger}$ Total does not add to nine due to missing data

"The diagnosis can be a problem; they (patients) have a lot of nonspecific symptoms. From an epidemiological point of view, their profiles as to age, gender, and so on, overlap a lot with irritable bowel disease."

Gastroenterologists and GI nurses reported that diseaserelated abnormalities are not always obvious, making diagnosis difficult. Although multiple diagnostic tests are available, 73\% of gastroenterologists indicated in the survey that none give a clear diagnosis for CD (Table 2). Other key factors that gastroenterologists and GI nurses perceived as deterrents to optimal diagnosis were the need for multiple tests to rule out differential diagnoses, and their own lack of knowledge and skill in assessing pain effectively and objectively.

Patients confirmed the perceptions of GI professionals in their identification of challenges, indicating that they had difficulty describing their symptoms. They further reported that CD may be confused with other common symptoms or conditions. They described diagnosis as a frustrating process, during which they felt 'alone with their symptoms'. As stated by this patient: 
TABLE 2

Challenges to diagnosis of Crohn's disease identified by Canadian gastroenterologists: Phase II $(n=37)$

\begin{tabular}{lcc}
\hline & \multicolumn{2}{c}{ Level of challenge to optimal care* } \\
\cline { 2 - 3 } Challenge/barrier & Mean & $\begin{array}{c}\text { Gastroenterologists } \\
\text { scoring 3-5, } \mathbf{n} \text { (\%) }\end{array}$ \\
\hline $\begin{array}{l}\text { Nonspecific symptoms of Crohn's } \\
\text { disease }\end{array}$ & 3.22 & $30(81)$ \\
$\begin{array}{l}\text { Inaccuracy of tests to diagnose } \\
\text { Crohn's disease }\end{array}$ & 2.97 & $27(73)$ \\
$\begin{array}{l}\text { Multiple tests required to accurately } \\
\text { diagnose Crohn's disease }\end{array}$ & 2.95 & $23(62)$ \\
\hline
\end{tabular}

*1 = Not at all, 3 = Moderately, 5 = To a great extent. Sixty-two per cent to 81\% of gastroenterologists identified diagnosis of Crohn's disease as a moderate or greater barrier in their practice on a five-point Likert scale in the survey

TABLE 3

Knowledge gaps of gastroenterologists in the treatment of patients with Crohn's disease: Phase II - survey $(n=37)$

\begin{tabular}{lccc}
\hline & \multicolumn{2}{c}{ Level of knowledge } \\
Component of treatment & 2.69 & 3.36 & $0.67^{\star}$ \\
\cline { 2 - 3 } (1 = Low, $\mathbf{5}=$ High), mean & \\
\cline { 2 - 3 } Optimal care for children & Current & Desired & Gap \\
Optimal care for pregnant women & 3.67 & 4.64 & $0.97^{\star \star}$ \\
Step-up versus top-down therapy & 4.22 & 4.76 & $0.53^{\star \star}$ \\
Pros and cons of treatment options & 4.35 & 4.86 & $0.51^{\star \star}$ \\
Immunogenicity & 3.57 & 4.46 & $0.89^{\star \star}$ \\
Nonpharmacological treatment & 3.24 & 4.51 & $\mathbf{1 . 2 7}$ \\
Safety and side effects & 4.22 & 4.86 & $0.65^{\star \star}$ \\
\hline
\end{tabular}

Paired-samples t test revealed significant gaps between current and desired levels of knowledge $\left({ }^{\star} P<0.01,{ }^{* *} P<0.001\right)$. Substantive gaps between current levels of knowledge and desired levels of knowledge of one or greater are indicated in bold

"It's hard to describe (the pain) and it's hard to get people to understand what you're going through."

\section{Gaps in treatment}

Gastroenterologists reported that they lack knowledge and confidence when treating certain subgroups of patients with $\mathrm{CD}$, particularly pregnant women (Table 3 ). One gastroenterologist's expression of this gap was:

"An important area in inflammatory bowel disease that still needs more attention is pregnancy."

Gastroenterologists attributed this gap to the infrequency with which they manage patients in subgroups such as children and pregnant women, and their uncertainty regarding pharmacological and nonpharmacological management of these patients.

GI nurses had several significant knowledge gaps relating to treatment of CD (Table 4), including the optimal care of children and pregnant women, step-up versus top-down therapy, the risks and benefits of treatment, immunogenicity, nonpharmacological treatment options, and drug safety and side effects.

Gastroenterologists and GI nurses reported knowledge gaps with regard to biological therapy. They had a limited awareness of clinical trials of biologicals and of which agents are approved for use in Canada. Gastroenterologists lacked the clinical awareness of how to introduce biologicals, use them in combination therapy, prescribe optimal doses or deal effectively with adverse effects. As stated by two gastroenterologists:

\section{TABLE 4}

Knowledge gaps of gastroenterology nurses in the treatment of patients with Crohn's disease: Phase II survey $(n=36)$

\begin{tabular}{|c|c|c|c|}
\hline \multirow[b]{2}{*}{ Component of treatment } & \multicolumn{2}{|c|}{$\begin{array}{c}\text { Level of knowledge } \\
\text { (1 = Low, } 5=\text { High), mean }\end{array}$} & \multirow[b]{2}{*}{ Gap } \\
\hline & Current & Desired & \\
\hline Optimal care for children & 2.00 & 3.56 & $1.56^{*}$ \\
\hline Optimal care for pregnant women & 2.00 & 3.92 & $1.92^{*}$ \\
\hline Step-up versus top-down therapy & 2.67 & 4.58 & $1.91^{*}$ \\
\hline Pros and cons of treatment options & 3.14 & 4.77 & $1.63^{*}$ \\
\hline Immunogenicity & 2.40 & 4.37 & $1.97^{*}$ \\
\hline Nonpharmacological treatment & 2.43 & 4.54 & $2.11^{*}$ \\
\hline Safety and side effects & 3.26 & 4.71 & $1.45^{\star}$ \\
\hline
\end{tabular}

Paired samples t test revealed significant gaps between current and desired level of knowledge $\left({ }^{*} P<0.001\right)$. Substantive gaps between current levels of knowledge and desired levels of knowledge of one or greater are indicated in bold

"In terms of biologic therapy, just as a general brush, it's not something I'm comfortable yet with early introduction"; and

"I really want to have confidence that I'm not setting people up for problems in two decades!"

Fifty-four per cent of gastroenterologists identified a lack of confidence in the early introduction of biologicals as a moderate to great barrier to optimal patient care. Other factors contributing to a lack of confidence in prescribing biologicals included concerns about what to do if biologicals fail, and doubts regarding the long-term safety and side effects of these agents, of which $27 \%$ of gastroenterologists and $40 \%$ of GI nurses identified as a moderate to greater barrier to optimal patient care. The trade-off between the treatment of CD, side effects, and quality of life was identified as a moderate to great barrier to optimal patient care by $54 \%$ of gastroenterologists and $55 \%$ of GI nurses.

CD patients and GI nurses reported that many patients were not actively engaged in therapeutic decisions. The lack of engagement was attributed to a cultural belief that 'doctors know best', the patients' belief that they lack sufficient knowledge to contribute to the decision-making process and a challenge that gastroenterologists face due to a lack of skill to engage their patients in treatment decisions.

Patients were aware that a lack of adherence to prescribed therapy would affect care outcomes. They attributed nonadherence to several factors: trial-and-error approach to treatment, (eg, switching from drugs that cause side effects), concerns regarding the long-term use of drugs and negative cultural beliefs about drugs. Patients reported that a gastroenterologist who prescribes a drug causing too many side effects loses the patient's confidence in treatment decisions. Patients were aware of the consequences of nonadherence to therapy (eg, exacerbations, complications and disability).

\section{Gaps in patient monitoring}

Gastroenterologists reported a lack of the necessary skills and knowledge to effectively monitor disease activity and patient response to therapy. They stated that they were unfamiliar with monitoring tools and objective measures of disease progression and do not have confidence in their skill for the optimal 
selection and timing of monitoring tests. Instead, they tended to rely on patients' subjective reports of symptoms and wellbeing as their primary strategy for monitoring CD. They expressed little confidence in this strategy, however, believing it to be unreliable because patients lack the awareness and skill to interpret their body responses and identify symptoms accurately. Gastroenterologists expressed particular concerns about basing a decision to discontinue treatment on patients' selfassessment of symptoms.

\section{Gaps in patient management}

All participants reported suboptimal collaboration among health care providers who care for patients with CD and identified a shortage of GI nurses to provide patient support. Subjects also indicated that allied health care providers, including dieticians, social workers and psychologists are underused. Neither patients nor physicians were convinced that these professionals could help, and gastroenterologists often failed to inform patients of their benefits. Physicians often did not know what allied health care resources were available or to whom to refer.

The participants reported that gastroenterologists conduct most patient education, despite limitations of time and educational skill. As stated in this interview with a gastroenterologist:

"A lot of these people (patients with CD) need some counselling and support to get through that...I try to do it, but I'm very pressed for time and I'm probably not very good at it."

Due to the resulting lack of education regarding CD, patients tend to 'suffer in silence' and play a lesser role in selfmanagement.

\section{DISCUSSION}

The Canadian gastroenterologists and GI nurses who participated in the present needs assessment identified important gaps in the care of patients with CD. To summarize, these gaps centred on challenges in optimal diagnosis, knowledge and confidence in biological therapies, skills and confidence in monitoring disease activity, challenges in providing emotional support and patient education, and clarity in the roles of all members of the health care team. Each of these challenges has implications for the care provided to patients. Challenges in diagnosing CD make the road to recovery both lengthy and frustrating for patients. Gaps in knowledge and confidence in managing specific patient subgroups, such as children and pregnant women, can result in a reluctance to intervene and undertreatment. For gastroenterologists, knowledge gaps regarding biological therapy led to a lack of confidence in prescribing these agents.

Concerns about the trade-off between drug risks and benefits may restrict gastroenterologists from introducing more aggressive therapy; however, recent findings from the United Kingdom (17) have shown that patients with CD are more willing than their physicians to accept a greater risk of serious adverse events in exchange for clinical efficacy, particularly to relieve the severity of daily symptoms. Physicians may benefit from a better understanding of patients' risk tolerance. Increasing physician knowledge of the current research evidence regarding efficacy, risks and benefits of these agents would also support decision-making regarding optimal treatments for individual patients.
Gastroenterologists reported that they lacked the skills and knowledge to monitor disease activity and patient response to therapy, relying primarily on patients' self-reporting. Inaccurate assessment of disease activity can lead to under- or overtreatment. Furthermore, gastroenterologists who cannot adequately assess a patient's response to therapy due to a lack of monitoring tools, as well as a lack of knowledge of those that are available, risk losing the patient's confidence and impairing the therapeutic relationship.

Specific challenges to the therapeutic relationship between gastroenterologists and their patients were identified in the present needs assessment. Gastroenterologists generally reported being unable to allocate the time necessary to educate patients about their disease, work with them to improve their perceptions and attitudes about $\mathrm{CD}$, encourage them to take a proactive stance toward self-management or involve them in treatment decisions. These deficits suggest that patients do not have the necessary information or emotional/ psychological support to mange their CD effectively. Because patients may be less willing to question or participate in decisions, they may be nonadherent to prescribed therapy, with the attendant risks of increased disease activity, complications and disability.

Teamwork among health care professionals was found to present its own challenges. According to the study participants, roles within the team became confused when gastroenterologists provided both primary and specialized care. When followed by both PCPs and gastroenterologists, patients may be required to assume the role of communicator and coordinator between the two professional groups. Furthermore, communication gaps between team members can result in delay in diagnosis, repetition of diagnostic and monitoring tests, and delayed follow-up and management.

Gastroenterologists in the present needs assessment were not able to capitalize on the strengths of interdisciplinary health care teams, possibly because of limited access to other team members, and/or lack of familiarity with the skills and potential contributions of other professionals. Underuse and limited access to allied health care professionals may heighten patient frustration, further promoting nonadherence. Psychological stress is often implicated as an exacerbating factor in CD; gastroenterologists may under-recognize the impact of a lack of access to allied health care professionals who provide patient education, as well as psychological or social support. Also, the lack of structured teamwork in the care of CD patients may lead patients to visit emergency rooms for disease monitoring, where staff may lack the expertise to diagnose and treat the symptoms of CD.

The CanMEDS 2005 Physician Competency Framework (8) as well as other professional organizations $(9,10)$ emphasize the broader role of the physician in providing health care, which encompasses not only medical expertise but also the roles of communicator and collaborator. These competencies are reflected in the findings of the present study for which participants expressed difficulties in communicating and supporting patients, and in collaborating with interdisciplinary team members.

The findings of the present study suggest a need for educational initiatives that promote knowledge and skill in diagnosing, treating and managing patients with CD. These should be 
provided in a practical clinical context that is relevant to everyday practice, with explicit, clear, clinically relevant guidelines and facilitated communication among all members of the health care team. Educational programs need to incorporate care in the larger context of the patient-professional therapeutic relationship, including communication, education and emotional support of patients, as well as defining clear roles for all members of the interdisciplinary team.

Recognition of the context in which care is provided is critical in designing educational initiatives that positively impact clinical practice and patient outcomes. Gaps in knowledge can be addressed by programs providing information; however, such programs must further address translation of this knowledge into practice in the actual clinical setting. Educational initiatives should similarly address situations in which there is no strong evidence to guide diagnostic and treatment decisions. Gastroenterologists require guidance in addressing uncertainties both in decision making with respect to treatment and in communicating with patients. Examples include decisions regarding the long-term effect of treatment options, and treatment and management of subpopulations such as pregnant women - decisions for which the evidence does not provide clear direction. Challenges in communication and therapeutic relationship skills require realistic solutions that are applicable to busy practices and practitioners. Such initiatives may take many forms beyond the traditional methods of education of health care professionals, such as point-of-care patient education and communication tools that can be implemented within the time constraints of a busy practice.

\section{Limitations}

The present needs assessment focused on challenges to clinical practice, barriers to change and knowledge gaps. Areas in which gastroenterologists, GI nurses and patients with CD have reported adequate patient care were not addressed.

\section{REFERENCES}

1. Economou M, Pappas, G. New global map of Crohn's disease: Genetic, environmental, and socioeconomic conditions. Inflamm Bowel Dis 2008;14:709-20.

2. Lowe AM, Roy PO, B-Poulin M, et al. Epidemiology of Crohn's disease in Quebec, Canada. Inflamm Bowel Dis 2009;15:429-35.

3. Bernstein CN, Wajda A, Svenson LW, et al. The epidemiology of inflammatory bowel disease in Canada: A population-based study. Am J Gastroenterol 2006;101:1559-68.

4. Bernstein $\mathrm{CN}$, Nabalamba A. Hospitalization, surgery, and readmission rates of IBD in Canada: A population-based study. Am J Gastroenterol 2006;101:110-8.

5. Longobardi T, Jacobs P, Wu L, Bernstein CN. Work losses related to inflammatory bowel disease in Canada: Results from a national population health survey. Am J Gastroenterol 2003;98:844-9.

6. Ghosh S, Mitchell R. Impact of inflammatory bowel disease on quality of life: Results of the European Foundation of Crohn's and Colitis Association's [EFCCA] patient survey. J Crohn's Colitis 2007;1:10-20.

7. Westwood N, Travis SPL. What do patients with inflammatory bowel disease want for their clinical management? Aliment Pharmacol Ther 2008;27(Suppl 1):1-8.

8. Frank JR. The CanMEDS 1005 physician competency framework. Better standards. Better physicians. Better care. Ottawa: The Royal College of Physicians and Surgeons of Canada, 2005. <http://rcpsc.
The sample size for the qualitative interviews was appropriate for this type of research. Despite the small number of participants in the survey, the total population sampled was similarly small. The number of participants represented slightly more than $10 \%$ of Canadian gastroenterologists.

An additional limitation in identifying gaps involving PCPs was that no PCPs participated in the present needs assessment; their perspective is not included directly, instead, it was inferred from the reports of gastroenterologists, GI nurses and patients.

\section{CONCLUSION}

The objective of the present needs assessment was to determine the educational needs of gastroenterologists and GI nurses who care for patients with CD. Based on the findings of the present study, educational gaps and barriers to change exist in all aspects of managing CD patients, from timely access to care through diagnosis, treatment and patient monitoring. It is important for gastroenterologists and GI nurses to seek ways to address these gaps to improve their clinical practices. In addition, these educational needs are important to address when framing clinical practice guidelines for optimal patient care.

ACKNOWLEDGEMENTS: This needs assessment was conducted by the AXDEV Group (Brossard, Quebec). The authors acknowledge the contribution of Heather Pengelley, who provided medical writing services under contract to AXDEV Group. Ms Pengelley reports no conflicts of interest. Invaluable support was provided by Michael W Foster and Elaine L Turner, Project Coordinators, Performance Optimization, AXDEV Group. We express our appreciation for the contributions of the gastroenterologists, gastroenterology nurses, and patients who gave their time and experience to this research.

FUNDING: This study was funded with the support of an unrestricted educational research grant from Abbott Laboratories Ltd, Canada.

medical.org/canmeds/CanMEDS2005/CanMEDS2005_e.pdf> (Version current at January 2, 2009).

9. American Board of Medical Specialties (ABMS). <http://www. abms.org/Maintenance_of_Certification/MOC_competencies.aspx $>$ (Version current at October 1, 2009).

10. ACGME Competencies. < http://www.acgme.org/outcome/comp/ GeneralCompetenciesStandards21307.pdf > (Version current at October 1, 2009).

11. Chatterji M. Evidence on "What works": An argument for extended-term mixed method (ETMM) evaluation designs. Educational Researcher 2005;34:14-24.

12. Johnson RB, Onwuegbuzie AJ. Mixed methods research: A research paradigm whose time has come. Educational Researcher 2004;33:14-26.

13. Denzin NK, Lincoln YS, eds. Handbook of Qualitative Research. 2nd edn. Thousand Oaks: Sage Publications, 2000.

14. Creswell JW. Research Design: Qualitative, Quantitative, and Mixed Approaches. Thousand Oaks: Sage Publications, 2003.

15. Strauss A, Corbin J. Basics of qualitative research: Grounded Theory Procedures and Techniques. Newbury Park: Sage Publications, 1990.

16. Neuendorf KA. The Content Analysis Guidebook. Thousand Oaks: Sage Publications, 2002.

17. Johnson FR, Ozdemir S, Mansfield C, et al. Crohn's disease patients' risk-benefit preferences: Serious adverse event risks versus treatment efficacy. Gastroenterology 2007;133:769-79. 


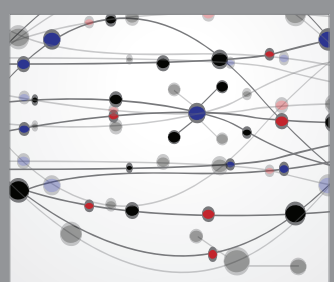

The Scientific World Journal
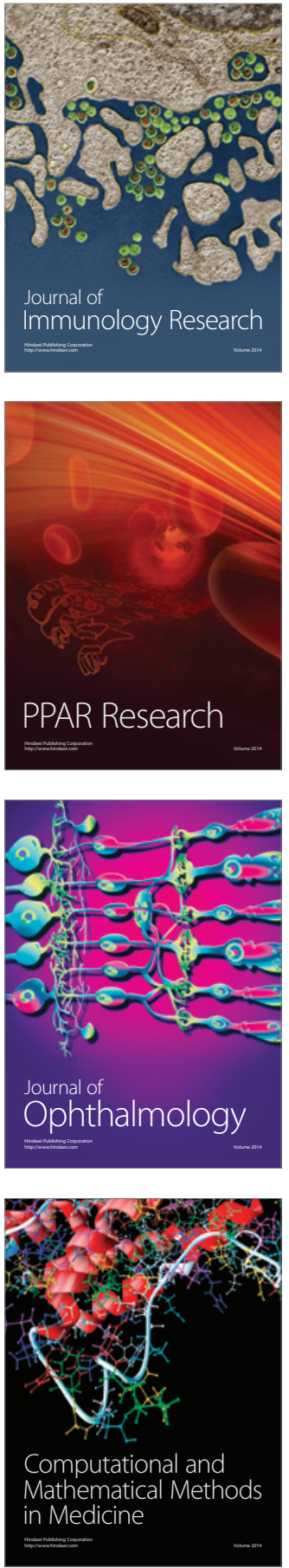

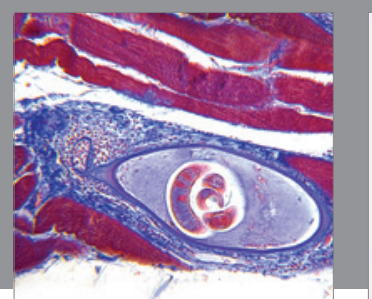

Gastroenterology Research and Practice

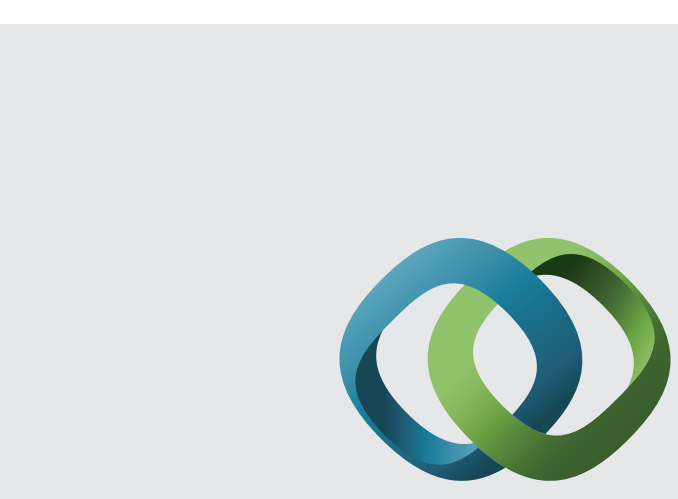

\section{Hindawi}

Submit your manuscripts at

http://www.hindawi.com
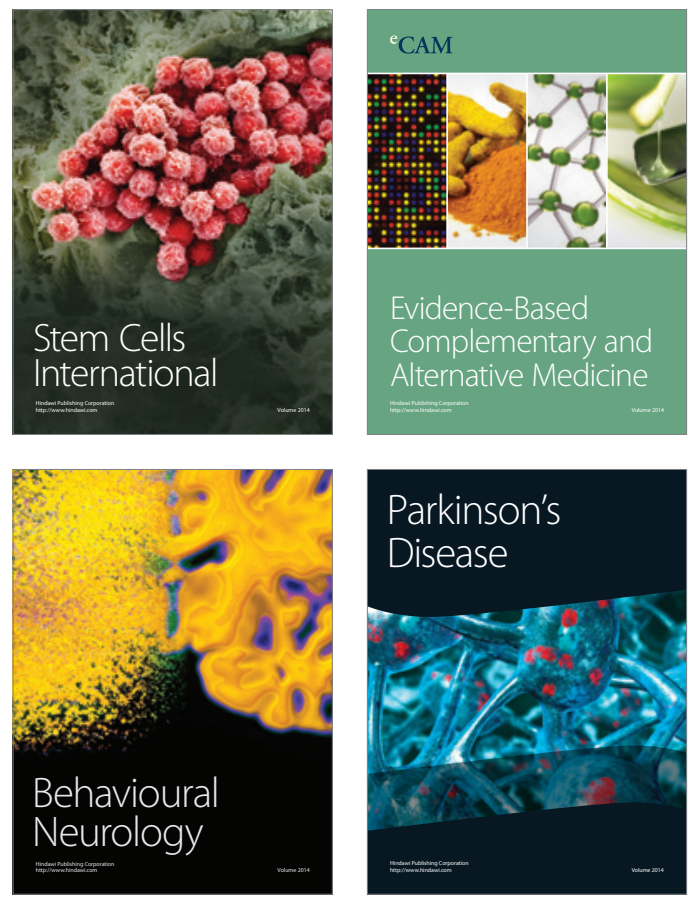
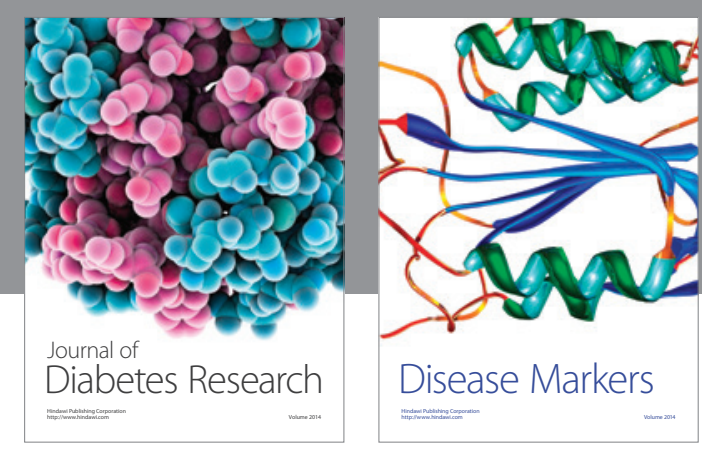

Disease Markers
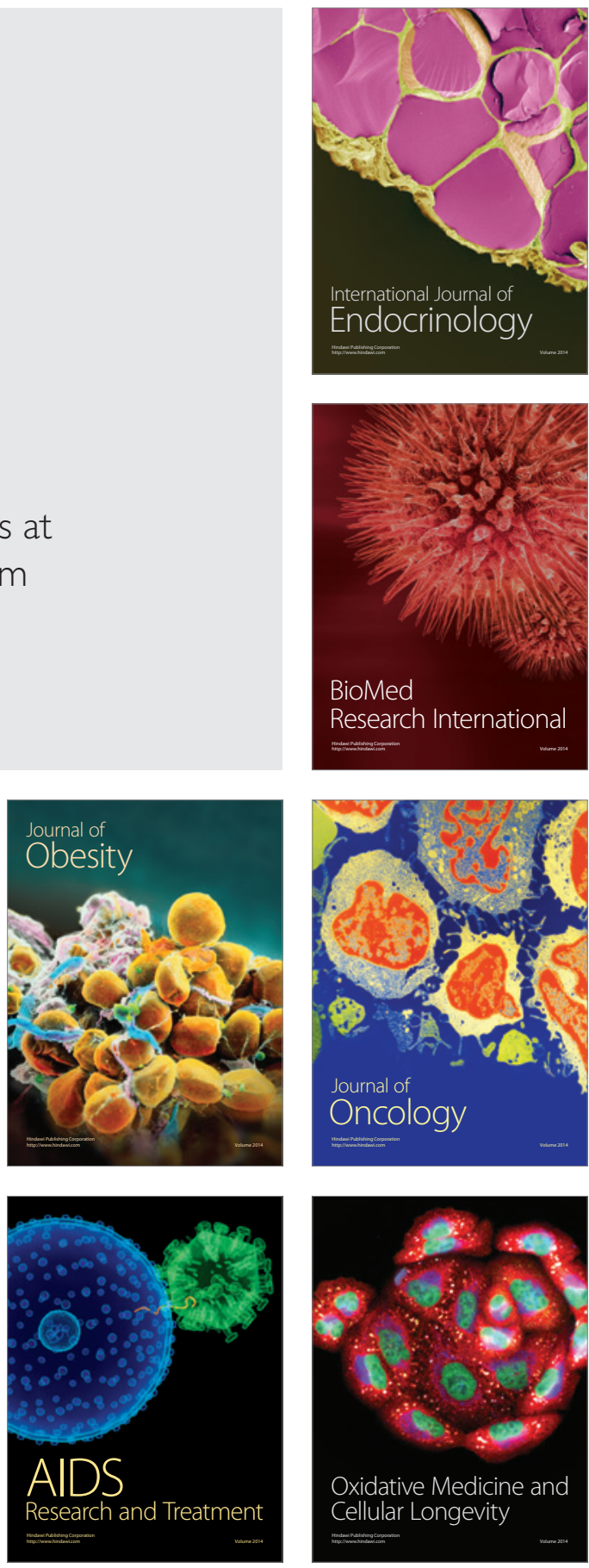